\title{
PERANCANGAN SISTEM MANAJEMEN RUANG KULIAH MENGGUNAKAN JARINGAN SYARAF TIRUAN (STUDI KASUS PADA FIKST UNIVERSITAS DHYANA PURA)
}

\author{
I Gusti Ngurah Anom Cahyadi Putra ${ }^{1)}$ Made Agung Raharja ${ }^{2)}$ \\ Prodi Teknik Informatika, Fakultas Ilmu Kesehatan Sains dan Teknologi ${ }^{12)}$ \\ Universitas Dhyana Pura, Badung, Bali \\ anom.cp@gmail.com ${ }^{1)}$ mdagungraharja@gmail.com ${ }^{2}$ )
}

\begin{abstract}
At the University of Dhyana Pura space management are tasked to regulate the use of lecture halls and laboratories. However, because the system used is still manual, so that the space management officers often have difficulty to regulate the use of lecture hall with the existing class schedule. Besides the issue of the use of space, space management also govern the use of space for small classes (less than 20 students) and large classes (students over 20) in order to be an effective use of space and the lecture can run well. Based on these events and so we need a system that can help the management space to set the schedule of lectures with the space available. With the system it is expected that the lecture can run properly fit the space available. The description above should be conducted early research on space management system design using neural networks. Neural network used is a method in which the perceptron neural network model was created to identify the class schedule based on the space available. Artificial neural network systems make the process of learning to adjust to pattern drafting scheduling.
\end{abstract}

Keywords: neural networks, perceptron

\begin{abstract}
ABSTRAK
Pada Universitas Dhyana Pura terdapat manajemen ruang yang bertugas untuk mengatur penggunaan ruang kuliah dan laboratorium. Namun karena sistem yang digunakan masih manual,sehingga sering kali petugas manajemen ruang mengalami kesulitan untuk mengatur penggunaan ruang kuliah dengan jadwal kuliah yang ada. Selain masalah penggunaan ruang, manajemen ruang juga mengatur penggunaan ruang untuk kelas kecil (mahasiswa kurang dari 20) dan kelas besar (mahasiswa lebih dari 20) agar penggunaan ruang menjadi efektif dan perkuliahan dapat berjalan dengan baik. Berdasarkan kejadian tersebut sehingga dibutuhkan suatu sistem yang dapat membantu manajemen ruang untuk mengatur antara jadwal kuliah dengan ruangan yang tersedia. Dengan adanya sistem maka diharapkan perkuliahan dapat berjalan dengan baik sesuai dengan ruang yang tersedia.Dari uraian diatas maka perlu dilakukan penelitian awal tentang perancangan sistem manajemen ruang menggunakan jaringan syaraf tiruan. Jaringan syaraf tiruan yang digunakan adalah metode perceptron dimana model jaringan syaraf tersebut dibuat untuk mengidentifikasikan jadwal kuliah berdasarkan ruangan yang tersedia. Sistem jaringan syaraf tiruan melakukan proses pembelajaran untuk menyesuaikan terhadap pola penyusunan penjadwalan.
\end{abstract}

Kata Kunci : Jaringan Syaraf Tiruan, Perceptron 


\section{PENDAHULUAN}

Pada Universitas Dhyana Pura terdapat manajemen ruang yang bertugas untuk mengatur penggunaan ruang kuliah dan laboratorium. Namun karena sistem yang digunakan masih manual,sehingga sering kali petugas manajemen ruang mengalami kesulitan untuk mengatur penggunaan ruang kuliah dengan jadwal kuliah yang ada. Selain masalah penggunaan ruang, manajemen ruang juga mengatur penggunaan ruang untuk kelas kecil (mahasiswa kurang dari 20) dan kelas besar (mahasiswa lebih dari 20) agar penggunaan ruang menjadi efektif dan perkuliahan dapat berjalan dengan baik.

Namun dikarenakan sistem yang digu-nakan masih manual sehingga manajemen ruang juga mengalami kesulitan untuk me-ngatur antara ruang yang tersedia dengan jadwal yang ada. Saat ini gedung D uni-versitas dhyana pura digunakan oleh fakultas ilmu kesehatan sains dan teknologi. Ditam-bah fakta bahwa dari tahun ketahun jumlah mahasiswa semakin meningkat. Sehingga diperlukan suatu sistem yang dapat membantu manajemen ruang untuk mengatur jadwal kuliah agar perkuliahan dapat berjalan dengan baik.

Dengan menggunakan konsep jaringan syaraf tiruan dengan metode perceptron dimana model jaringan syaraf tiruan akan mengidentifikasikan jadwal kuliah dengan jumlah ruang yang tersedia. Sehingga diharapkan perkuliahan di fakultas ilmu kesehatan sains dan teknologi dapat berjalan dengan baik.

\section{TINJAUAN PUSTAKA}

Sistem adalah sekumpulan elemen yang saling terkait atau terpadu yang dimaksudkan untuk mencapai suatu tujuan (Kadir, 2003). Ada beberapa elemen yang membentuk sebuah sistem, yaitu: Tujuan, Masukan, Keluaran, Proses, Mekanisme pengendalian dan Umpan balik.

Jaringan syaraf tiruan (artificial neural network), atau disingkat JST, adalah sistem komputasi di mana arsitektur dan operasi diilhami dari pengetahuan tentang sel syaraf biologis di dalam otak, yang merupakan salah satu representasi buatan dari otak manusia yang selalu mencoba menstimulasi proses pembelajaran pada otak manusia tersebut. JST dapat digambarkan sebagai model matematis dan komputasi untuk fungsi aproksimasi non-linear, klasifikasi data cluster dan regresi non-parametrik atau sebuah simulasi dari koleksi model syaraf biologi.

Seperti halnya otak manusia, jaringan syaraf tiruan juga terdiri dari beberapa neuron dan ada hubungan antara neuron-neuron tersebut. Beberapa neuron akan mentransformasikan informasi yang diterimanya melalui sambungan keluaran menuju neuron lainnya. Dengan kata lain, neuron/sel syaraf adalah sebuah unit pemroses informasi yang merupakan dasar operasi jaringan syaraf tiruan. Gambar 1 di menunjukkan contoh suatu neuron.

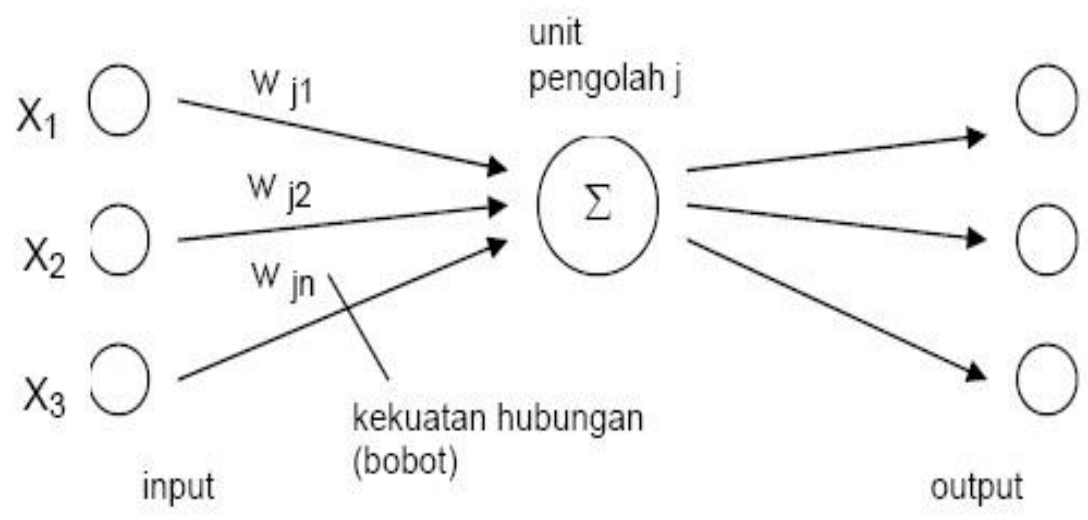

Gambar 1. Struktur Jaringan Syaraf Tiruan 
Model jaringan perceptron ditemukan oleh Rosenblatt (1962) dan Minsky - Papert (1969). Model tersebut merupakan model yang memiliki aplikasi dan pelatihan yang paling baik pada era tersebut. Perceptron lapis tunggal dapat dikatakan sebagai salah satu teknik jaringan syaraf tiruan yang sederhana. Umumnya, perceptron digunakan untuk mengklasifikasikan suatu pola tertentu.

Arsitektur jaringan perceptron mirip dengan arsitektur jaringan Hebb. Jaringan terdiri dari beberapa unit masukan ( ditambah sebuah bias ), dan memiliki sebuah unit keluaran. Hanya saja fungsi aktivasi merupakan fungsi biner ( atau bipolar ), tetapi memiliki kemungkinan nilai -1, 0 atau 1 .

Untuk suatu harga threshold $\theta$ yang ditentukan :

$$
f(n e t)=\left[\begin{array}{cl}
1 & \text { Jika net }>\theta \\
0 & \text { jika }-\theta \leq \text { net } \leq \theta \\
-1 & \text { jika net }<-\theta
\end{array}\right.
$$

Algoritma pelatihan perceptron adalah sebagai berikut, misalkan $\mathrm{S}$ adalah vector masukan dan $\mathrm{t}$ adalah target keluaran $\alpha$ adalah laju pemahaman ( learning rate ) yang ditentukan $\theta$ adalah threshold yang ditentukan. Inisialisasi semua bobot dan bias ( umumnya wi = b 0 ), Menentukan laju pemahaman $(=\alpha)$.
Untuk penyederhanaan biasanya $\alpha$ diberi nilai $=1$ Selama ada elemen vector masukan yang respon unit keluarannya tidak sama dengan target, lakukan : Set aktivasi unit masukan $x i=\operatorname{si}(i=1, \ldots n)$, Hitung respon unit keluaran : net $=\Sigma$ xiwi $+\mathrm{b}$

$$
f(n e t)=\left[\begin{array}{cl}
1 & \text { Jika net }>\theta \\
0 & \text { jika }-\theta \leq \text { net } \leq \theta \\
-1 & \text { jika net }<-\theta
\end{array}\right.
$$

Perbaiki bobot pola yang mengandung kesalahan $(\mathrm{y} \neq \mathrm{t})$ menurut persamaan :

$\mathrm{Wi}($ baru $)=$ wi $($ lama $)+\Delta \mathrm{w}(\mathrm{i}=1, \ldots \mathrm{n})$

dengan $\Delta \mathrm{w}=\alpha \mathrm{t}$ xi

$\mathrm{b}($ baru $)=\mathrm{b}($ lama $)+\Delta \mathrm{b}$ dengan $\Delta \mathrm{b}=\alpha \mathrm{t}$

Database (basis data) berasal dari kata basis yang artinya markas atau tempat berkumpul dan data yang artinya kumpulan faktra yang mewakili suatu objek seperti manusia, konsep,dan peristiwa. Database adalah kumpulan data yang saling berhubungan, diorganisasikan dengan baik agar tidak terjadi redudansi (pengulan) dan inkonsistensi dan disimpan dalam media elektronis.

Untuk mengelola database digunakan DBMS (Database Management Sistem) untuk melakukan manajemen basis data dan berinteraksi dengan apliaksi pengguna dalam aplikasi ini DBMS merupakan back end (database yang mendukung aplikasi) yaitu : Oracle, MS SQL, Microsoft Access,SQLite.

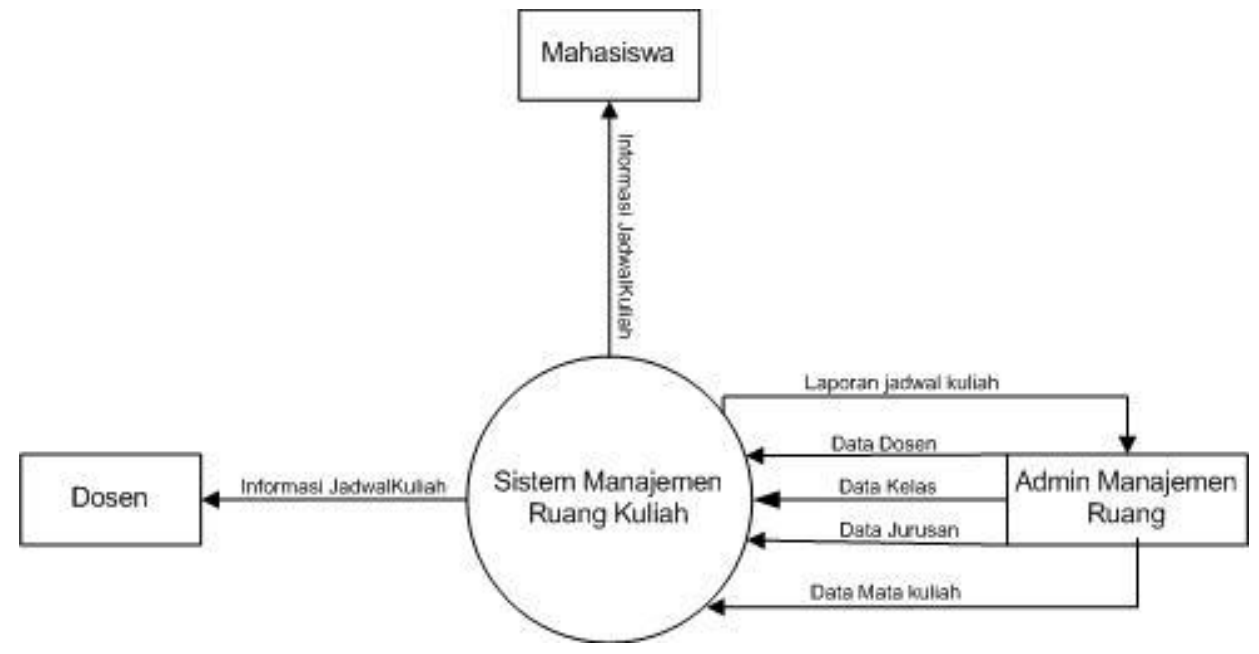

Gambar 2. Perancangan DFD level 0 


\section{METODE PENELITIAN}

Jenis penelitian yang dilakukan adalah kuantitatif dimana dengan menghitung perhitungan jadwal dengan menggunakan rumus matematis dari metode pada jaringan syaraf tiruan. Waktu dan tempat penelitian dilakukan selama 5 bulan, bertempat di Lab Komputer Universitas Dhyana Pura.

Pengembangan adalah suatu pendekatan yang sangat rapi dan berurutan untuk membuat sebuah sistem menjadi suatu kenyataan. Diperlukan suatu rancangan metodologi untuk menyediakan suatu struktur pengembangan sistem. Ada banyak siklus hidup pengembangan sistem (SDLC) "tradisional" untuk sistem informasi. Yang terdiri antara lain:

\section{Perencanaan}

Fase perencanaan memulai dengan sebuah kebutuhan bisnis yang belum terpenuhi. Meliputi peluang-peluang yang mungkin yang diidentifikasi dengan membaca lingkungan. Apakah ada suatu masalah yang harus dipecahkan? Inisiasi proyek melibatkan sebuah sistem yang telah diputuskan. Jika kelihatan bermanfaat, maka dilakukan (analisis) studi kelayakan. Studi kelayakan ini mempertimbangkan apakah gagasan tersebut masuk akal, jika disetujui maka ditugaskanlah seorang manajer proyek ntuk menyusun sebuah rencana kerja, mengorganisasi proyek, dan mengadopsi metodemetode untuk mengelolanya.

\section{Analisis}

Fase analisis seperti wawancara pada kontraktor. Fase ini menanyakan dan menjawab pertanyaan-pertanyaan penting seperti siapa para pengguna system, apa yang akan dicapai oleh system, dan dimana dan kapan system akan dijalankan. Fase ini memulai dengan mengembangkan sebuah strategi analisis atau suatu rencana untuk memandu proyek. Jika sebelumnya sudah ada sistem yang berjalan, maka sistem tersebut dianalisis bersama dengan berbagai cara untuk mengarah kepada sistem yang baru. Hal ini memimpin kepada pengumpulan informasi lebih lanjut, pengembangan subuah model proses dan model data.

\section{Desain}

Fase desain menandai bagaimana sistem akan bekerja, mempertimbangkan semua detail perangkat keras, perangkat lunak, infrastruktur jaringan, antar muka pengguna, dan seterusnya. Pada fase ini antarmuka pengguna, form, display, program dan laporan, database dan file ditetapkan.

\section{Implementasi}

Fase ini merupakan tempat dimana sistem dibangun. Kontruksi melibatkan tidak hanya membangun sistem , tetapi juga mengujinya untuk memverifikasi bahwa sistem bekerja. Instalasi merupakan langkah terakhir dan melibatkan apakah sistem benar-benar berjalan.

\section{HASIL DAN PEMBAHASAN}

Pada saat ini gedung D memiliki 10 ruang kelas dan manajemen ruang masih menggunakan sistem manual dalam mem-buat jadwal perkuliahan. Analisis yang didapat adalah sebagai berikut: Ketua program studi memberikan data jurusan pada manajemen ruang. Ketua program studi memberikan data mata kuliah yang akan dibuka pada semester tersebut pada mana-jemen ruang Ketua program studi mem-berikan data dosen yang mengajar atau mengampu mata kuliah tersebut Ketua program studi memberikan jumlah maha-siswa dan jumlah kelas pada mata kuliah tersebut Manajemen ruang membuat jadwal kuliah dari setiap program studi yang menggunakan gedung $\mathrm{D}$ berdasarkan data mata kuliah, data dosen, data program studi, dan data jumlah siswa.

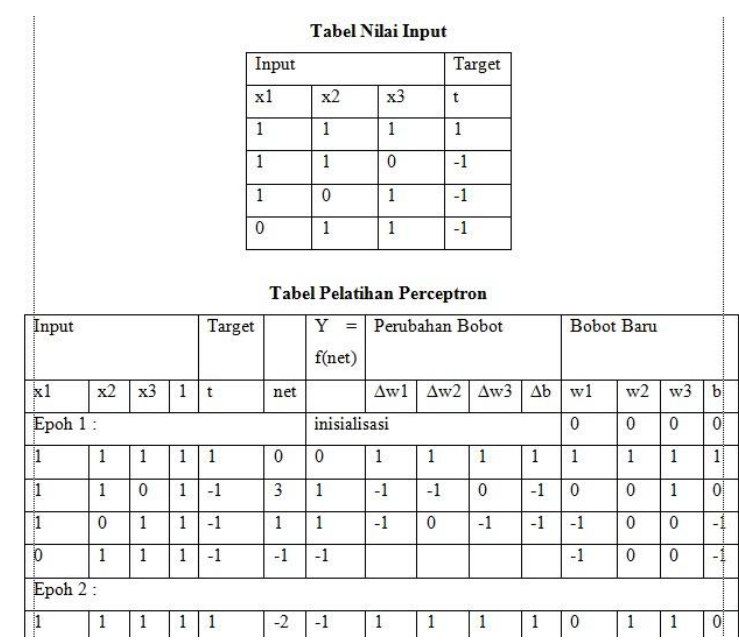

Gambar 3. Model JST 


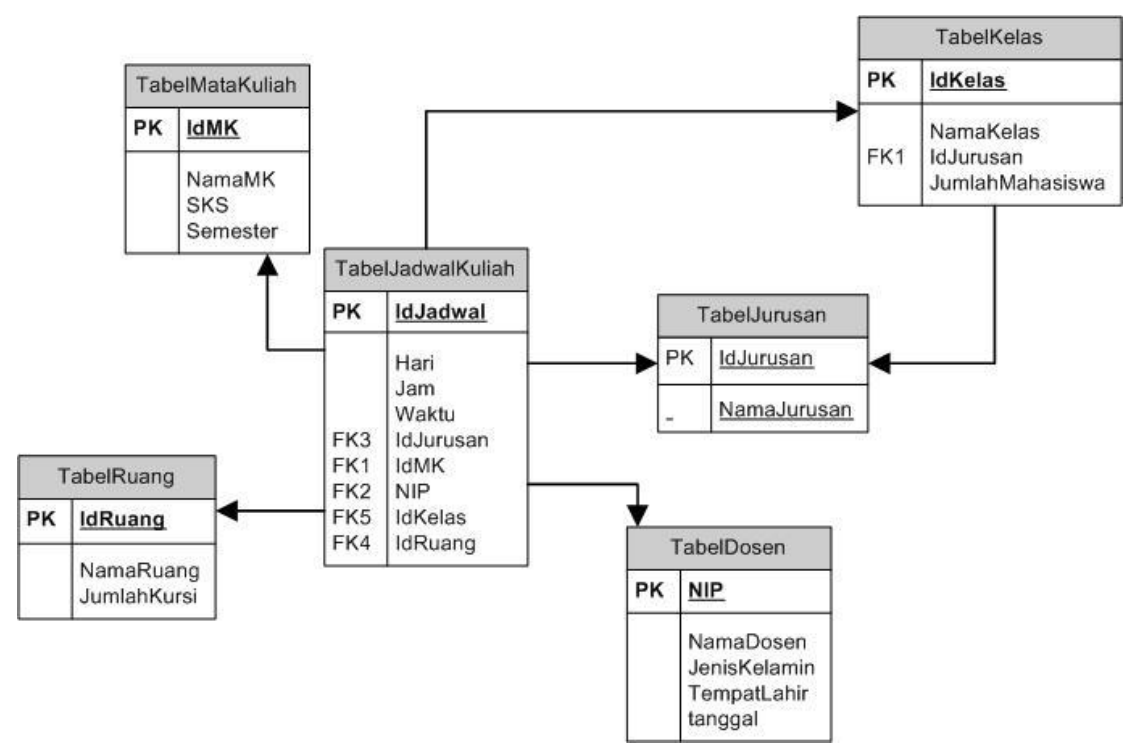

Gambar 4. Perancangan Relasi Antar Tabel

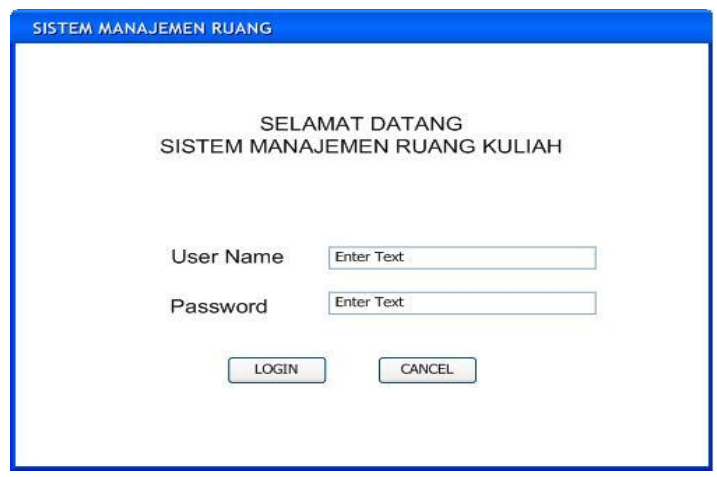

Gambar 5. Perancangan User Interface 


\section{SIMPULAN}

Berdasarkan hasil yang dicapai terkait dengan analisis dan perancangan sistem manajemen ruang, maka didapat kesimpulan sebagai berikut: mengetahui kelemahan dari sistem yang sedang berjalan setelah melakukan analisis sistem, merancang kebutuhan user dalam peran-cangan sistem manajemen ruang, dapat merancang sistem dan basis data dari sistem manajemen ruang.

\section{DAFTAR PUSTAKA}

[1] Arif Hermawan, Jaringan Saraf Tiruan, Teori dan Aplikasi. Yogyakarta, ANDI, 2006.

[2] Diyah Puspitaningrum, Pengantar Jaringan Saraf Tiruan, Andi, Jakarta, 2006.

[3] Jaja Jamaludin Malik, Tip \& Trik Unik Delphi Lanjutan, Andi, Jakarta, 2006. [4] Jong Jek Siang, Jaringan Syaraf Tiruan dan Pemrogramannya Menggunakan Matlab, Andi, Yogyakarta, 2009.

[5] Mike Susmikanti dan Arya Adhiyaksa, Identifikasi Huruf Menggunakan Metode Pembelajaran Perceptron Dalam Jaringan Neural, Prosiding Semiloka Teknologi Simulasi dan Komputasi serta Aplikasi, Pusat Pengembangan Teknologi Informasi dan Komputasi-BATAN, 2005, hlm 1-9.

[6] Siska Primangingrum (Penterjemah), Sistem Pendukung Keputusan Dan Sistem Cerdas, Jilid 2, Andi, Yogyakarta, 2005.

[7] Wahana Komputer, Membuat Program Kreatif dan Profesional dengan Delphi, PT Elex Media Komputindo, Jakarta, 2005. [8] Yahya Yanuar, Pemrograman Delphi dengan Database Microsorft SQL Server, PT Elex Media Komputindo, Jakarta, 2004 